\title{
Anion exchange membranes with eight flexible side-chain cations for improved conductivity and alkaline stability
}

\author{
Chenyi Wang ${ }^{1 *}$, Zhengwang Tao ${ }^{1}$, Yuanpeng Zhou ${ }^{1}$, Xiaoyan Zhao ${ }^{1}$, Jian Li $^{1}$, Qiang Ren ${ }^{1}$ and \\ Michael D. Guiver ${ }^{2,3^{*}}$
}

\begin{abstract}
Increasing the local charge density of flexible side-chain cations in the hydrophilic segments of anion exchange membranes (AEMs) is helpful for improving their properties. However, due to limitations of structural design strategies and available synthetic methods, very few AEMs with more than four flexible side-chain cationic groups in hydrophilic segments have been reported. In order to further improve the hydroxide conductivity, alkaline stability and dimensional stability, herein we report a series of AEMs containing eight flexible side-chain cations in hydrophilic segments, based on poly(aryl ether sulfone)s (PAES). The synthesis, ion exchange capacity (IEC), water absorption, dimensional swelling, alkaline stability and hydroxide conductivity of the obtained membranes (PAES-8TMA-x) were examined and the relationships between structures and properties of different types of AEMs were also systematically compared. The resulting AEMs with IEC values of 1.76-2.76 $\mathrm{mmol} \mathrm{g}^{-1}$ displayed comprehensively desirable properties, with hydroxide conductivities of 62.7$92.8 \mathrm{mS} \mathrm{cm}^{-1}$ and dimensional swelling in the range of $8.3 \%$ to $15.8 \%$ at $60^{\circ} \mathrm{C}$. The IEC and hydroxide conductivity for a representative sample, PAES-8TMA-0.35, maintained $82.2 \%$ and $79.6 \%$ of the initial values after being immersed in $2 \mathrm{~mol} \mathrm{~L}^{-1} \mathrm{NaOH}$ at $90^{\circ} \mathrm{C}$ for $480 \mathrm{~h}$, respectively. This study expands the design and preparation of AEMs containing high local densities of flexible side chain cations, and provides a new strategy for new AEM materials.
\end{abstract}

Keywords: anion exchange membrane, conductivity, alkaline stability, flexible side chain

\section{INTRODUCTION}

Owing to increasing worldwide energy usage and environmental pollution, the research and development of clean and high-efficiency energy conversion devices have important significance and practical value [1-3]. Fuel cells are recognized as highly efficient energy conversion devices, because they can convert chemical energy directly from fuels and oxidants into electrical energy [4]. Proton exchange membrane fuel cells (PEMFCs) are a type of fuel cells that use cation exchange polymeric membranes as electrolytes. They have attracted wide attention due to their advantages of high power density, small size, light weight, low operating temperature, and short cold start interval [5], and have been utilized in many areas, such as aerospace, vehicles, stationery and home power supplies. Perfluorosulfonic acid Nafion ${ }^{\circledR}$ polymer electrolyte membranes produced by DuPont have been primarily used in commercial PEMFCs. Although these electrolyte membranes possess excellent physical, chemical and electrochemical properties, they incur high production costs and high fuel permeability [6]. At the same time, because of the low electrode reactivity and acidic operating environment, PEMFCs require the use of noble metal catalysts and highly pure fuels to minimize catalyst poisoning, which limits their widespread use. Therefore, research attention has been directed towards lower-cost PEMFCs with high electrode reactivity.

In contrast with PEMFCs, anion exchange membrane fuel cells (AEMFCs) operate under alkaline conditions, and the cathode reaction kinetics is greatly improved.

\footnotetext{
${ }^{1}$ Jiangsu Collaborative Innovation Center of Photovoltaic Science and Engineering, Jiangsu Key Laboratory of Environmentally Friendly Polymeric Materials, School of Materials Science and Engineering, Changzhou University, Changzhou 213164, China

${ }^{2}$ State Key Laboratory of Engines, Tianjin University, Tianjin 300072, China

${ }^{3}$ Collaborative Innovation Center of Chemical Science and Engineering (Tianjin), Tianjin 300072, China

* Corresponding authors (emails: wangcy@cczu.edu.cn (Wang C); michael.guiver@outlook.com (Guiver M))
} 
Consequently, the range of effective catalysts is extended to non-precious metals such as nickel or silver [7], which is of great significance for reducing costs, since noble metal catalysts comprise the major cost of a fuel cell stack. As one of the important components of AEMFCs, the properties of anion exchange membranes (AEMs) directly affect the performance and service life of fuel cells under strong alkaline working conditions [8]. Ideal AEMs should have high hydroxide conductivity, low dimensional swelling ratio under high water absorption, and good chemical stability and mechanical properties [9]. Many AEMs reported in recent years have some shortcomings, including low ion conductivity and poor alkaline stability [10]. To improve hydroxide conductivity and alkaline stability under strong alkaline conditions, AEMs with different macromolecular architectures have been prepared, such as main chain type [11], block type $[12,13]$, side chain type $[14,15]$, comb-shaped type [16], hyperbranched [17] and mobile ion shuttles [18]. The polymer backbones employed include polyolefins [19], poly(phenylene oxide)s [20], poly(aryl ether sulfone)s (PAES) [21,22], poly(arylene ether ketone)s [23,24], poly(aryl ether nitrile)s [25], poly(benzimidazole)s [26], and numerous other structures [27]. The functional groups for the preparation of AEMs mainly consist of quaternary ammonium [28,29], imidazole [30,31], quaternary phosphornium [32], guanidine [33] and metalbased cations [34]. Among them, quaternary ammonium cations are currently the most likely functional group to be industrially applied to AEMs given their lower price and simpler synthetic methods.

Cationic groups in most AEMs previously reported are often bonded to the polymer backbone through one methylene linkage. Despite their uncomplicated synthetic approach, they typically have low hydroxide conductivity, resulting from low cation flexibility and a low propensity for forming microphase separated morphology [35]. In addition, because the cationic groups are benzylic, the cation and polymer backbone induce each other to promote degradation when attacked by hydroxide ions, thus reducing the overall alkaline stability of the polymer backbone and cation site [36]. On the other hand, a block copolymer AEM architecture is conducive to the formation of more defined hydrophilic/hydrophobic microphase separated morphology, thus greatly improving ion conduction [37]. However, block copolymer-type AEMs typically have a large ion channel size accompanied by high dimensional water swelling ratio, which leads to inferior mechanical properties and even a loss of mechanical strength under high temperature conditions
[38]. Furthermore, the alkaline stability is generally not significantly improved compared with main chain-type AEMs. In addition, block-type AEMs are synthesized by batch feeding and multi-step reactions, which is a more cumbersome process [39]. Recent studies suggest that the mutual degradative induction effect between cation and polymer backbone is suppressed by introducing flexible alkyl side chains to distance the cationic site from the backbone, thereby improving the alkaline stability of cation and polymer backbone simultaneously [40]. Quaternary ammonium cations attached to flexible alkyl side chains are also effective in enhancing the self-assembly of ions within the membrane morphology [41]. Therefore, using this approach, the microphase separated morphology can be improved, thus increasing the hydroxide conductivity and water resistance of the membrane [42].

Further increasing the local density of flexible sidechain cations in the hydrophilic segments of AEMs is anticipated to increase the aggregation of the flexible side chain cations and the polarity difference between the hydrophobic polymer backbone and the hydrophilic side chain, thereby promoting microphase separation and improving the properties. Zhu et al. [43] studied poly (phenylene ether)-based AEMs grafted with single flexible side chains bearing three quaternary ammonium cations. One AEM with an ion exchange capacity (IEC) value of $3.07 \mathrm{mmol} \mathrm{g}^{-1}$ had good hydroxide conductivity (99 mS cm$~^{-1}$ at room temperature), favorable alkaline stability $\left(90 \%\right.$ ion conductivity retention in $1 \mathrm{~mol} \mathrm{~L}^{-1}$ $\mathrm{NaOH}$ at $80^{\circ} \mathrm{C}$ for $500 \mathrm{~h}$ ) and acceptable swelling ratio (31\% at room temperature). Dang et al. [44] investigated poly(phenylene ether)-based AEMs containing four flexible piperidine ions on flexible side chains. One AEM with an IEC value of $2.6 \mathrm{mmol} \mathrm{g}^{-1}$ had a high hydroxide conductivity of $221 \mathrm{mS} \mathrm{cm}^{-1}$ at $80^{\circ} \mathrm{C}$, with $86 \%$ ion conductivity retention in $1 \mathrm{~mol} \mathrm{~L}^{-1} \mathrm{NaOH}$ at $90^{\circ} \mathrm{C}$ for $240 \mathrm{~h}$. These examples indicate that by increasing the local density of cationic groups supported on flexible side chains, distant from the polymer backbone, improvements in ion conduction, alkaline and dimensional stability are realized. Because monomers containing multiple ions are difficult to purify and need to be synthesized by multi-step organic reactions, it is challenging to prepare side-chain AEMs with more than four cations in the repeat units.

In order to further enhance hydroxide conductivity, alkaline stability and dimensional stability, here we report a series of novel AEMs containing eight flexible sidechain cations in the hydrophilic repeat units. A bisfluorophenylsulfone monomer containing octamethoxy 
groups is first synthesized, from which a methoxy-substituted PAES is prepared by copolycondensation. Demethylation, followed by grafting, provides AEMs with eight flexible alkyl quaternary ammonium cations in each monomer segment. The synthesis, structure, IEC, water absorption, dimensional swelling, alkaline stability and hydroxide conductivity are examined in detail. The structure-property relationships of different types of AEMs are also systematically compared. To the best of our knowledge, no AEMs with eight side-chain flexible cations in hydrophilic units have been reported. This study further expands the structural architecture of AEMs containing high local density flexible side chain cations, and provides a new strategy for the preparation of AEM materials.

\section{EXPERIMENTAL SECTION}

Bis(4-fluorophenyl)sulfone (BFPS, recrystallized from ethanol), N-bromosuccinimide (NBS, 99\%), boron tribromide $\left(\mathrm{BBr}_{3}, 99.9 \%\right)$ and sodium hydride $(\mathrm{NaH}, 60 \%)$ were purchased from Shanghai Aladdin Reagent Co. Ltd. (China). 3,5-Dimethoxyphenylboronic acid (98\%) was obtained from Suzhou Sukailu Chemical Technology Co. Ltd. Tetrakis(triphenylphosphine)palladium(0) (99\%) was obtained from Shanghai Jizhi Biochemical Technology Co. Ltd. 4,4'-Dihydroxybiphenyl (BP, 98\%) and (5-bromopentyl)trimethylammonium bromide (BPTMA, 98\%) were purchased from J \& K Chemical. Other commercially available reagent-grade chemicals, $N$-methylpyrrolidone (NMP), dimethylacetamide (DMAc), tetrahydrofuran (THF) and other solvents were used directly as received.

\section{Synthesis of $3,3^{\prime}, 5,5^{\prime}$-tetrabromo-4,4'-difluorodiphenyl sulfone (TBDPS)}

The intermediate compound, TBDPS, was synthesized according to the method previously reported by our laboratory $[45,46]$.

\section{Synthesis of $3,3^{\prime}, 5,5^{\prime}$-tetra $\left(3^{\prime \prime}, 5^{\prime \prime}\right.$-dimethoxyphenyl)-4, $4^{\prime}$ - difluorodiphenyl sulfone (TDMPDPS)}

TBDPS (13.00 g, $23 \mathrm{mmol}), 17.65 \mathrm{~g}$ (97 mmol) of (3,5dimethoxyphenyl)boronic acid and $2.10 \mathrm{~g}(2 \mathrm{mmol})$ of tetrakis(triphenylphosphine)palladium $(0)$ were successively added to a 1-L three-neck round bottom flask equipped with a motorized stirrer, a reflux condenser and nitrogen as an inert atmosphere. Then, $200 \mathrm{~mL}$ of toluene and $40 \mathrm{~mL}$ of 1,2-dimethoxyethane as a mixed solvent were added into the flask. The mixture was stirred at $50^{\circ} \mathrm{C}$ until the solids were completely dissolved, then another $250 \mathrm{~mL}$ aqueous solution containing $42.00 \mathrm{~g}$ of sodium carbonate was added. After the mixture was stirred at $110^{\circ} \mathrm{C}$ for $10 \mathrm{~h}$, the organic layer was removed using a rotary evaporator to give crude product as a yellow solid, which was then dried and recrystallized from DMAc to obtain pure white crystals of TDMPDPS: 3,3',5,5'-tetra (3",5"-dimethoxyphenyl)-4,4'-difluorodiphenylsulfone. Yield: $68 \%$, mp: $255-256^{\circ} \mathrm{C}$. ${ }^{1} \mathrm{H}$ NMR (400 MHz, DMSO$\left.d_{6}, \mathrm{ppm}\right): \delta 3.78\left(\mathrm{~s}, 6 \mathrm{H}, \mathrm{H}_{4}\right), 6.60\left(\mathrm{t}, 1 \mathrm{H}, \mathrm{H}_{3}\right), 6.76(\mathrm{~s}, 2 \mathrm{H}$, $\left.\mathrm{H}_{2}\right), 8.28\left(\mathrm{~d}, 1 \mathrm{H}, \mathrm{H}_{1}\right) .{ }^{13} \mathrm{C} \mathrm{NMR}\left(100 \mathrm{MHz}, \mathrm{DMSO}-d_{6}\right.$, ppm): $55.83\left(\mathrm{C}_{\mathrm{b}}\right), 100.95\left(\mathrm{C}_{\mathrm{a}}\right), 107.97\left(\mathrm{C}_{\mathrm{d}}\right), 130.06\left(\mathrm{C}_{\mathrm{i}}\right)$, $131.30\left(\mathrm{C}_{\mathrm{f}}\right), 135.78\left(\mathrm{C}_{\mathrm{h}}\right), 137.98\left(\mathrm{C}_{\mathrm{e}}\right), 160.13,160.94\left(\mathrm{C}_{\mathrm{h}}\right)$, $160.96\left(\mathrm{C}_{\mathrm{c}}\right)$.

\section{Synthesis of PAES with eight methoxybenzene (PAES- $\left.\mathbf{8 O C H}_{3}-x\right)$}

PAES- $8 \mathrm{OCH}_{3}-x$ copolymers were synthesized by polycondensation, where $x$ is the molar ratio of TDMPDPS in the total difluorodiphenylsulfone monomers. As a typical example, PAES- $8 \mathrm{OCH}_{3}-0.25$ copolymer was prepared as follows: $1.5977 \mathrm{~g}(2.0 \mathrm{mmol})$ of TDMPDPS, $1.5255 \mathrm{~g}$ $(6.0 \mathrm{mmol})$ of BFPS, $1.4897 \mathrm{~g}(8.0 \mathrm{mmol})$ of BP, $2.66 \mathrm{~g}$ $(19.2 \mathrm{mmol})$ of $\mathrm{K}_{2} \mathrm{CO}_{3}, 15 \mathrm{~mL}$ of $\mathrm{NMP}$, and $6 \mathrm{~mL}$ of toluene were successively added to a $100-\mathrm{mL}$ three-neck round bottom flask equipped with a motorized stirrer, a Dean-Stark trap, a reflux condenser and a nitrogen inlet. The generated water and toluene were distilled out through azeotropic distillation after preheating at $140^{\circ} \mathrm{C}$ for $1 \mathrm{~h}$. Then, the temperature was increased to $160^{\circ} \mathrm{C}$ and the reaction was stirred for another 4-6 h. During the reaction, the color gradually deepened, from an initially clear colorless liquid to a pale-yellow turbid liquid until a viscous taupe-colored liquid developed. Finally, $5 \mathrm{~mL}$ of NMP was added to reduce the solution viscosity. After stirring well, the mixture was poured slowly into a stirred $500 \mathrm{~mL}$ ethanol/water solution $(V: V=1: 1)$ to precipitate out fibrous copolymer. The copolymer was further washed several times with ethanol and warm water, and then dried at $80^{\circ} \mathrm{C}$ for $24 \mathrm{~h}$.

Synthesis of PAES with eight hydroxylbenzene (PAES-8OH- $x$ ) PAES- $8 \mathrm{OCH}_{3}-0.25$ (3.30 g, $12.30 \mathrm{mmol}-\mathrm{OCH}_{3}$ groups) was dissolved in $100 \mathrm{~mL}$ of chloroform in a $250-\mathrm{mL}$ threenecked flask, using a mechanical stirrer and nitrogen inlet at room temperature. $\mathrm{BBr}_{3}(4.0 \mathrm{~mL})$ mixed with $50 \mathrm{~mL}$ of chloroform was added dropwise into the solution at $0^{\circ} \mathrm{C}$. After $30 \mathrm{~min}$, the reaction was stirred at room temperature for another 6-7 h. The mixture was poured slowly into a stirred $500 \mathrm{~mL}$ ethanol/water solution $(V: V=1: 1)$ to precipitate out fibrous copolymer, which was subsequently filtered and washed thoroughly with a large excess of ice 
water, to yield an off-white solid. After drying, the crude product was dissolved in an appropriate amount of DMAc, and then again slowly poured into a stirred $500 \mathrm{~mL}$ ethanol/water solution $(V: V=1: 1)$. The purified white filamentous product (PAES-8OH-0.25) was soaked in hot distilled water to remove reaction products and then dried in a vacuum oven at $80^{\circ} \mathrm{C}$ for $24 \mathrm{~h}$.

Synthesis of side-chain quaternized PAES (PAES-8TMA- $x$ ) PAES-8OH-0.25 (1.0 g, $4.03 \mathrm{mmol}-\mathrm{OH}$ groups) was dissolved in $15 \mathrm{~mL}$ of NMP in a $100-\mathrm{mL}$ three-necked flask with a mechanical stirrer and nitrogen inlet under heating. The polymer solution was cooled using an ice bath, and then $0.32 \mathrm{~g}(8.06 \mathrm{mmol})$ of sodium hydride was added and stirring was continued for $30 \mathrm{~min}$. Then, BPTMA $(2.33 \mathrm{~g}, 8.06 \mathrm{mmol})$ was added and the reaction mixture was stirred at $90^{\circ} \mathrm{C}$ for $6-8 \mathrm{~h}$ under nitrogen atmosphere. Then the mixture was cooled to room temperature and dispersed in $200 \mathrm{~mL}$ of acetone (or isopropanol). The flocculated polymer was filtered and washed thoroughly with a large amount of ethanol to remove impurities. The white polymer (PAES-8TMA0.25 ) was then dried in a vacuum oven at $80^{\circ} \mathrm{C}$ for $12 \mathrm{~h}$.

\section{RESULTS AND DISCUSSION}

\section{Synthesis and characterization of monomer}

A novel difluorodiphenylsulfone monomer TDMPDPS containing four 3,5-dimethoxybenzene pendant groups was synthesized in two-steps, as shown in Scheme 1a. First, an intermediate TBDPS was prepared by bromination of bis(4-fluorophenyl)sulfone at $60^{\circ} \mathrm{C}$ with NBS, using concentrated sulfuric acid as catalyst and solvent. Then, TBDPS reacted with 3,5-dimethoxybenzeneboronic acid by Suzuki coupling with tetrakis(triphenylphosphine)palladium(0) catalyst in an alkaline environment, giving a new difluorophenylsulfone monomer TDMPDPS.

The structure of monomer TDMPDPS was characterized by nuclear magnetic resonance (NMR) spectroscopy. Fig. 1a shows the ${ }^{1} \mathrm{H}$ NMR spectrum of monomer TDMPDPS. In the aromatic region, proton $\mathrm{H}_{1}$ is the most downfield singlet at $8.25 \mathrm{ppm}$, because of the strong electron-withdrawing effect of the sulfone linkage. The chemical shifts of the side chain benzene ring $\mathrm{H}_{2}$ and $\mathrm{H}_{3}$ protons are 6.76 and $6.60 \mathrm{ppm}$, respectively, due to the electron donating effect of the methoxy groups. The proton $\mathrm{H}_{4}$ on the methoxy groups appears at the highest field with a chemical shift of $3.78 \mathrm{ppm}$. The measured relative integrated area of each proton signal is $\mathrm{S}_{1}: \mathrm{S}_{2}: \mathrm{S}_{3}: \mathrm{S}_{4}=$ 1.00:2.05:1.02:6.09, which is approximately consistent with the theoretical values. Fig. $1 \mathrm{~b}$ shows the ${ }^{13} \mathrm{C}$ NMR spectrum of monomer TDMPDPS. $\mathrm{C}_{\mathrm{h}}$ has signals at 160.13 and $160.97 \mathrm{ppm}$ due to the strong induction effect of fluorine atoms. Fig. $1 \mathrm{c}$ shows the $2 \mathrm{D}^{1} \mathrm{H}_{-}{ }^{13} \mathrm{C}$ chemical-shift correlation spectroscopy (COSY) spectrum of monomer
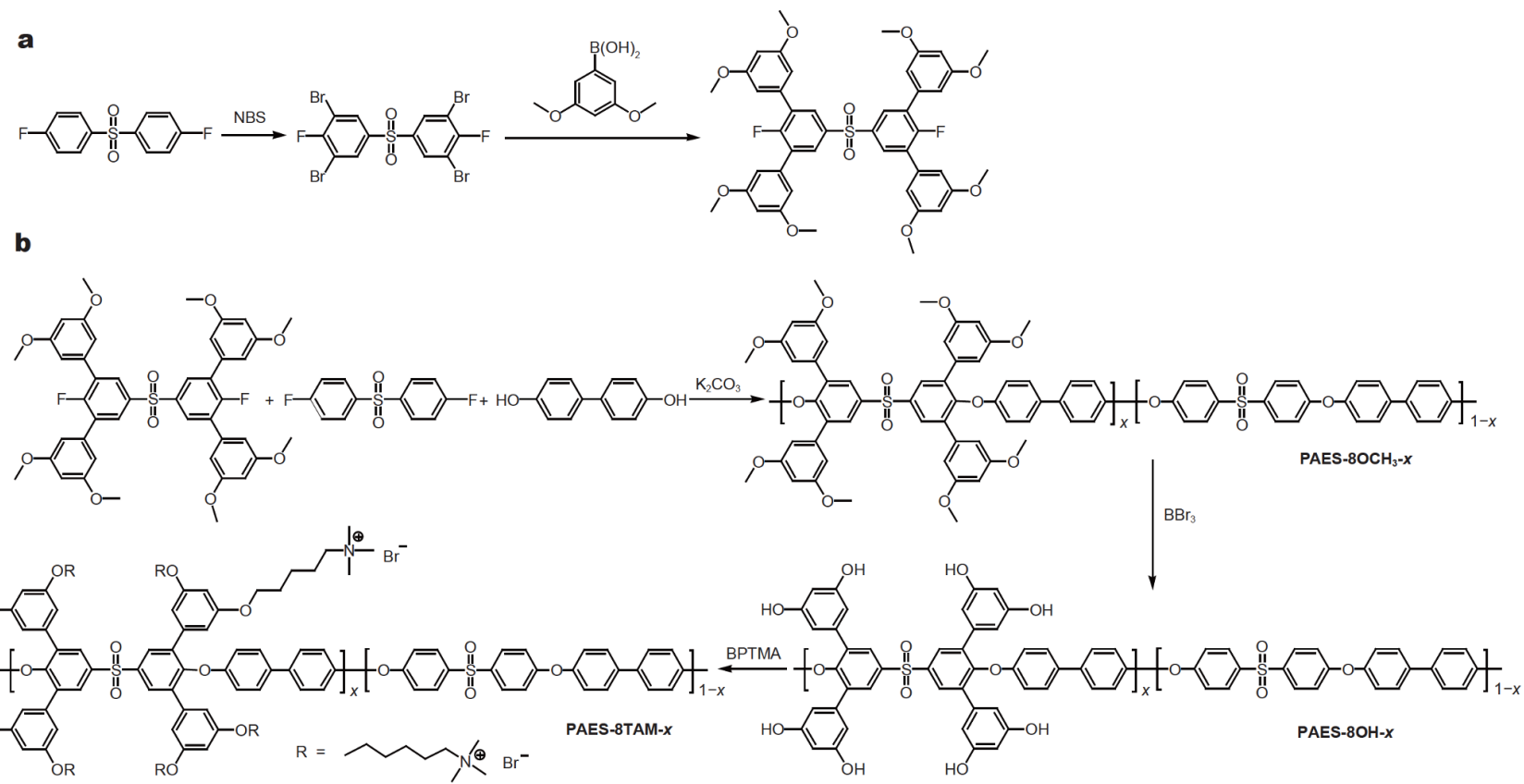

Scheme 1 Synthetic routes for (a) TDMPDPS and (b) the copolymers. 

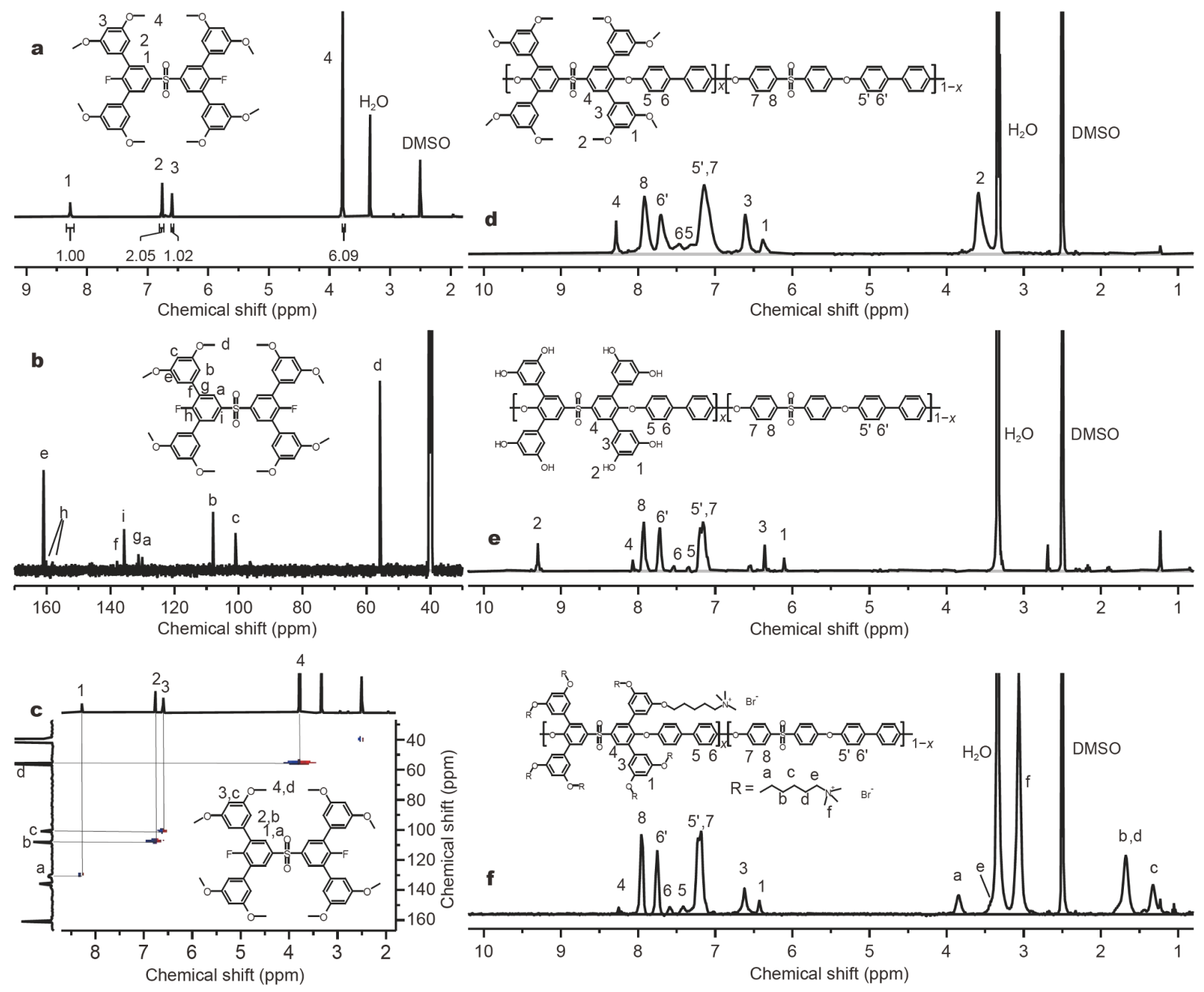

Figure 1 (a) ${ }^{1} \mathrm{H}$ NMR, (b) ${ }^{13} \mathrm{C}$ NMR and (c) ${ }^{1} \mathrm{H}^{13}{ }^{13} \mathrm{C}$ COSY spectra of the monomer TDMPDPS; ${ }^{1} \mathrm{H}$ NMR spectra of (d) PAES-8OCH ${ }_{3}-0.35$, (e) PAES$8 \mathrm{OH}-0.35$ and (f) PAES-8TMA-0.35.

TDMPDPS. The chemical shifts of $\mathrm{C}_{\mathrm{a}}, \mathrm{C}_{\mathrm{b}}, \mathrm{C}_{\mathrm{c}}$, and $\mathrm{C}_{\mathrm{d}}$ corresponding to $\mathrm{H}_{1}, \mathrm{H}_{2}, \mathrm{H}_{3}$, and $\mathrm{H}_{4}$ are at $130.06,107.98$, 100.95 , and $55.83 \mathrm{ppm}$, respectively. The NMR spectra verify the structure of the difluorophenylsulfone monomer having four 3,5-dimethoxybenzene substituents.

A series of PAES copolymers (PAES- $8 \mathrm{OCH}_{3}-x(x=$ $0.15,0.20,0.25,0.30,0.35)$ ) containing 3,5-dimethoxybenzene as pendant groups was synthesized by aromatic nucleophilic substitution polycondensation, by adjusting the monomer ratio TDMPDPS and bis(4-fluorophenyl) sulfone with 4,4'-biphenol. The synthetic route is shown in Scheme 1b. Table S1 lists the gel permeation chromatography (GPC) data and intrinsic viscosity $\left(\eta_{\text {inh }}\right)$ of copolymers PAES- $8 \mathrm{OCH}_{3}-x$. The number average molecular weights of PAES- $8 \mathrm{OCH}_{3}-x$ are in the range of $7.8 \times$
$10^{4}-9.8 \times 10^{4}$, the weight average molecular weights are between $14.0 \times 10^{4}$ and $21.1 \times 10^{4}$, the polymer dispersity index values are between 1.80 and 2.15. The intrinsic viscosity $\eta_{\text {inh }}$ values are between 0.66 and 1.09 . The GPC and intrinsic viscosity data confirm the copolymers have high molecular weights and moderate polydispersity indices. The ${ }^{1} \mathrm{H}$ NMR spectrum of PAES- $8 \mathrm{OCH}_{3}-0.35$ is shown in Fig. 1d. The $-\mathrm{OCH}_{3}$ proton $\left(\mathrm{H}_{2}\right)$ singlets appear at $3.59 \mathrm{ppm}, \mathrm{H}_{4}$ is affected by the sulfone group and the side chain benzene ring, and the chemical shift occurs at the lowest field of $8.27 \mathrm{ppm} . \mathrm{H}_{5}, \mathrm{H}_{5,7}, \mathrm{H}_{6}, \mathrm{H}_{6}, \mathrm{H}_{8}$ appear at 7.32, 7.13, 7.46, 7.70, $7.91 \mathrm{ppm}$, respectively.

The demethylation reaction of PAES- $8 \mathrm{OCH}_{3}-x$ with boron tribromide was carried out in chloroform solution for $6-7 \mathrm{~h}$, and the resulting copolymers with four 3,5- 
dihydroxybenzene as pendant groups (PAES- $8 \mathrm{OH}-x$ ) were obtained. The ${ }^{1} \mathrm{H}$ NMR spectrum of PAES- $8 \mathrm{OH}$ 0.35 is shown in Fig. 1e. The $-\mathrm{OCH}_{3}$ protons are absent, while a downfield signal at $9.30 \mathrm{ppm}$ corresponding to -OH appears, which confirms a complete conversion from $-\mathrm{OCH}_{3}$ to $-\mathrm{OH}$. Since the side chain benzene ring is affected by the electron donating effect of $-\mathrm{OH}$, the chemical shifts of $\mathrm{H}_{1}$ and $\mathrm{H}_{3}$ move to higher field at 6.11 and $6.36 \mathrm{ppm}$, respectively. Grafting of the quaternary ammonium group was accomplished by a Williamson etherification reaction. PAES- $8 \mathrm{OH}-x$ copolymers in the presence of $\mathrm{NaH}$ reacted with BPTMA to graft the flexible quaternary ammonium cation side-chain to obtain PAES8TMA- $x$ copolymers. The ${ }^{1} \mathrm{H}$ NMR spectrum of PAES8TMA-0.35 is shown in Fig. 1f. The absence of $-\mathrm{OH}$ protons and the appearance of new proton signals corresponding to $-\mathrm{CH}_{2}-$ and $-\mathrm{CH}_{3}$ appear at $3.83,3.40,3.07$, 1.67 and $1.32 \mathrm{ppm}$, respectively. The conversion of $-\mathrm{OH}$ to oxyalkyl groups results in downfield shifts for $\mathrm{H}_{1}$ and $\mathrm{H}_{3}$, which appear at 6.43 and $6.62 \mathrm{ppm}$, respectively. The NMR spectra support the conversion of PAES- $8 \mathrm{OH}-0.35$ to PAES-8TMA-0.35.

\section{IEC, WU and SR}

The IEC values for PAES-8TMA- $x$ membranes in the $\mathrm{OH}^{-}$form are listed in Table 1. The IEC $\mathrm{Ctheo}_{\text {the }}$ values of the PAES-8TMA- $x$ were calculated from the monomer feed ratio to be between 1.88 and $2.92 \mathrm{mmol} \mathrm{g}^{-1}$. The $\mathrm{IEC}_{\exp }$ values obtained by titration are between 1.76 and $2.76 \mathrm{mmol} \mathrm{g}^{-1}$, which are reasonably consistent with the IEC $_{\text {theo }}$. Fig. $2 \mathrm{a}$ and $\mathrm{b}$ plot the water uptake (WU) and swelling ratio (SR) of PAES-8TMA- $x$ membranes in the $\mathrm{Br}^{-}$form with $\mathrm{IEC}_{\text {exp }}$ and temperature, respectively. These show the expected increasing trend with increasing temperature and IEC values. The water uptake and swelling ratio of the PAES-8TMA- $x$ membranes are listed in Table S2. Water uptake and swelling ratios at $30^{\circ} \mathrm{C}$ are in the range of $15.7 \%$ to $47.2 \%$ and $6.0 \%$ to $13.9 \%$, respectively, but are higher at $60^{\circ} \mathrm{C}$, in the range of $20.8 \%$ to $64.4 \%$ and $8.3 \%$ to $15.8 \%$, respectively. Compared with many aromatic AEMs, PAES-8TMA- $x$ membranes have moderate water absorption and low swelling ratios, and water absorption and swelling ratio change more gradually with temperature at higher IEC levels. For example, PAES-8TMA-0.35 (IEC $\left.=2.76 \mathrm{mmol} \mathrm{g}^{-1}\right)$ had a water uptake of $47.2 \%$ and a swelling ratio of $13.9 \%$ at $30^{\circ} \mathrm{C}$, which at $60^{\circ} \mathrm{C}$, increased to $64.4 \%$ and $15.8 \%$, respectively. In comparison, imidazolium-functionalized PAES (ImPES-0.40, IEC $=1.82 \mathrm{mmol} \mathrm{g}^{-1}$ ) [30] had a water uptake of $31.5 \%$ and swelling ratio of $24.2 \%$ at $30^{\circ} \mathrm{C}$, which at $60^{\circ} \mathrm{C}$, increased to $40.9 \%$ and $35.3 \%$, respectively. A hyperbranched PAES (HBPAEK, IEC = $2.25 \mathrm{mmol} \mathrm{g}^{-1}$ ) [23] had a water uptake of $47.1 \%$ and swelling ratio of $26.5 \%$ at $20^{\circ} \mathrm{C}$, respectively, which at

Table 1 Ionic exchange capacity, hydroxide conductivity, $E_{\mathrm{a}}$ and mechanical properties of the PAES-8TMA- $x$

\begin{tabular}{|c|c|c|c|c|c|c|c|c|}
\hline \multirow{2}{*}{ Membrane } & \multicolumn{2}{|c|}{ IEC $\left(\mathrm{mmol} \mathrm{g}^{-1}\right)$} & \multicolumn{2}{|c|}{$\sigma\left(\mathrm{mS} \mathrm{cm}^{-1}\right)$} & \multirow{2}{*}{$E_{\mathrm{a}}\left(\mathrm{kJ} \mathrm{mol}^{-1}\right)$} & \multirow{2}{*}{$\mathrm{TS}^{\mathrm{c}}(\mathrm{MPa})$} & \multirow{2}{*}{$\mathrm{TM}^{\mathrm{d}}(\mathrm{GPa})$} & \multirow{2}{*}{$\mathrm{EB}^{\mathrm{e}}(\%)$} \\
\hline & theo. $^{\mathrm{a}}$ & exp. $^{\mathrm{b}}$ & $30^{\circ} \mathrm{C}$ & $60^{\circ} \mathrm{C}$ & & & & \\
\hline PAES-8TMA-0.15 & 1.88 & 1.76 & 33.4 & 62.7 & 18.4 & $35.4 \pm 1.2$ & $1.03 \pm 0.07$ & $13.4 \pm 1.3$ \\
\hline PAES-8TMA- 0.20 & 2.22 & 2.12 & 37.5 & 68.6 & 17.8 & $34.0 \pm 1.0$ & $1.01 \pm 0.08$ & $15.2 \pm 1.1$ \\
\hline PAES-8TMA- 0.25 & 2.50 & 2.35 & 40.4 & 73.7 & 17.2 & $32.4 \pm 1.1$ & $0.86 \pm 0.06$ & $16.9 \pm 1.2$ \\
\hline PAES-8TMA- 0.30 & 2.73 & 2.51 & 46.7 & 82.8 & 16.4 & $30.6 \pm 0.9$ & $0.70 \pm 0.06$ & $17.5 \pm 1.3$ \\
\hline PAES-8TMA-0.35 & 2.92 & 2.76 & 54.6 & 92.8 & 15.1 & $28.5 \pm 0.7$ & $0.58 \pm 0.05$ & $19.8 \pm 1.4$ \\
\hline
\end{tabular}

a) Calculated from the monomer ratio. b) Measured by back titration. c) Tensile strength. d) Tensile modulus. e) Elongation at break.
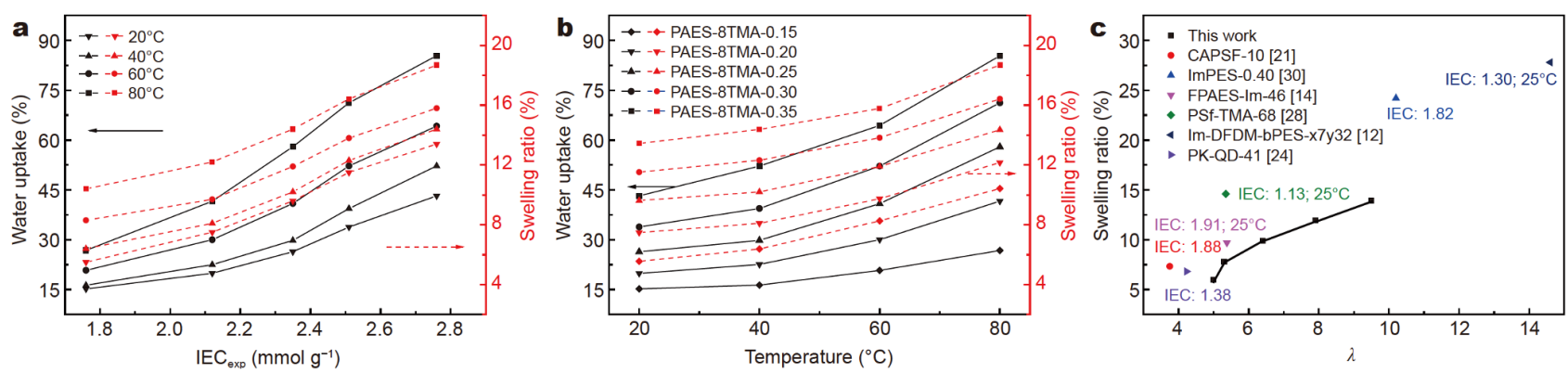

Figure 2 (a) Water uptake and (b) Swelling ratio of the PAES-8TMA- $x$ membranes. (c) Swelling ratio of PAES-8TMA- $x$ and other membranes versus $\lambda$ at $30^{\circ} \mathrm{C}$. 
$80^{\circ} \mathrm{C}$, increased to $58.6 \%$ and $48.1 \%$, respectively. The moderate water absorption and low dimensional swelling of the present PAES-8TMA- $x$ membranes are mainly due to a combination of the high local density and moderately long flexible side chain cations introduced into the polymer structure. The flexible side chains with cations at their termini not only provide a water space between the polymer chains, avoiding excessive dimensional swelling, but also facilitate aggregation or clustering of the cations to form a hydrophilic ionic network, resulting in better water distribution. The hydration numbers $(\lambda)$ of the PAES-8TMA- $x$ membranes are also listed in Table S2, and the $\lambda$ are between 5.0 and 9.5 at $30^{\circ} \mathrm{C}$.

Fig. $2 \mathrm{c}$ plots the swelling ratio and the $\lambda$ at $30^{\circ} \mathrm{C}$. As $\lambda$ increases, the swelling ratio gradually increases, but the rate of increase becomes less. Comparative data for other AEMs of similar IEC are also plotted. For example, for AEMs ImPES-0.40 (IEC $\left.=1.82 \mathrm{mmol} \mathrm{g}^{-1}, \lambda=10.2\right)$ [30] grafted with imidazolium-functionalized flexible side chains, CAPSF-10 (IEC $\left.=1.88 \mathrm{mmol} \mathrm{g}^{-1}, \lambda=3.8\right)$ [21] crosslinked with 4,4'-trimethylenedipiperidine, and FPAES-Im-46 (IEC $=1.91 \mathrm{mmol} \mathrm{g}^{-1}, \lambda=5.4$ at $\left.25^{\circ} \mathrm{C}\right)$ [14], the swelling ratios were $24.2 \%, 7.33 \%$, and $9.7 \%$, respectively, higher than PAES-8TMA-0.15 (IEC = $1.88 \mathrm{mmol} \mathrm{g}^{-1}, \lambda=5.0$ ). In addition, comparative AEMs with low IEC also show higher dimensional swelling than
PAES-8TMA- $x$. For example, the swelling ratio of PSfTMA-68 (IEC $=1.13 \mathrm{mmol} \mathrm{g}^{-1}, \lambda=5.4$ at $25^{\circ} \mathrm{C}$ ) [28], ImDFDM-bPES-x7y32 (IEC $=1.30 \mathrm{mmol} \mathrm{g}^{-1}, \lambda=14.6$ at $\left.25^{\circ} \mathrm{C}\right)[12]$ and PK-QD-41 (IEC $\left.=1.38 \mathrm{mmol} \mathrm{g}^{-1}, \lambda=4.2\right)$ [24] are $14.6 \%, 27.8 \%$ and $6.82 \%$, respectively. The comparative AEMs were above the PAES-8TMA- $x$ membrane curve, indicating that the increased swelling of these lower IEC AEMs is more closely correlated with water absorption. PAES-8TMA- $x$ has a moderate hydration number and a low swelling ratio, which may be the result of the locally dense cation distribution that can effectively control the water in the hydrophilic region and inhibit water absorption and dimensional swelling of the membrane.

\section{Hydroxide conductivity}

Fig. 3a shows the temperature dependence of hydroxide conductivity of PAES-8TMA- $x$ membranes. The trend is consistent with that of water uptake with increasing temperature. This trend is explained by the increase in anion diffusion rate with increasing temperature. Furthermore, with increases in water absorption, the tethered flexible quaternary ammonium groups have higher mobility, allowing better microphase separation and ion transport channel formation, leading to increased conductivity. The AEMs exhibit high hydroxide conductivity,
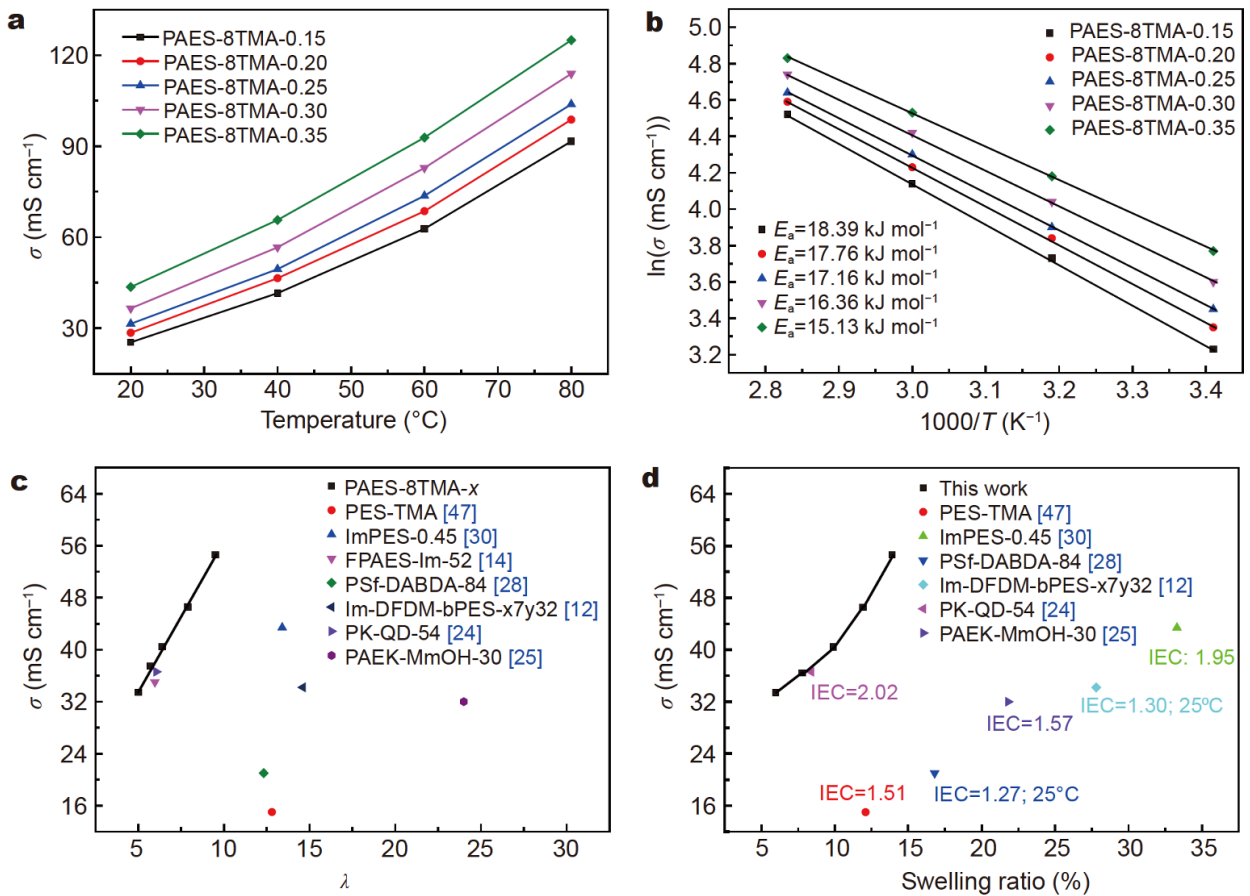

Figure 3 (a) Hydroxide conductivity, (b) Arrhenius plots of PAES-8TMA- $x$ versus temperature; hydroxide conductivity of PAES-8TMA- $x$ versus (c) $\lambda$ values and (d) swelling ratio at $30^{\circ} \mathrm{C}$. 
for example, PAES-8TMA-0.35 was 43.6 and $125.0 \mathrm{mS} \mathrm{cm}^{-1}$ at 20 and $80^{\circ} \mathrm{C}$, respectively. The activation energy $\left(E_{\mathrm{a}}\right)$ of hydroxide ion conduction was obtained from the $\ln (\sigma)-1000 / T$ curve of the membrane shown in Fig. $3 \mathrm{~b}\left(E_{\mathrm{a}}=-b \times R\right.$, where $b$ is the slope and $R$ is the universal gas constant). The $E_{\mathrm{a}}$ value is in the range of 15.1-18.4 $\mathrm{kJ} \mathrm{mol}^{-1}$; the PAES-8TMA-0.35 membrane with the highest hydroxide ion conductivity has the lowest activation energy. That is, the energy required for $\mathrm{OH}^{-}$to pass through the AEM is less. Partial hydroxide conductivity data and $E_{\mathrm{a}}$ values for the PAES-8TMA- $x$ membrane are listed in Table 1 .

Fig. $3 c$ shows the relationship between hydroxide ion conductivity and hydration number $\lambda$ at $30^{\circ} \mathrm{C}$. The hydroxide ion conductivity increases approximately linearly with $\lambda$. The higher the water absorption in the AEM, the more favorable the conduction of hydroxide ions are. Fig. $3 c$ also compares relevant data of some other reported AEMs. Those with comparable IEC values, such as PK-QD-54 (IEC = $\left.2.02 \mathrm{mmol} \mathrm{g}^{-1}, 36.6 \mathrm{mS} \mathrm{cm}^{-1}, \lambda=6.05\right)$ [24] have a similar hydroxide ion conductivity to the PAES-8TMA-0.15 membrane, but their $\lambda$ values are higher. Those with lower IEC values, such as PAEKMmOH-30 (IEC $=1.57 \mathrm{mmol} \mathrm{g}^{-1}, 32 \mathrm{mS} \mathrm{cm}^{-1}, \lambda=24$ ) [25] containing four flexible morpholine side chains, require higher $\lambda$ values to achieve similar hydroxide conductivity to the PAES-8TMA-0.15. Moreover, there are also some low IEC AEMs, such as PES-TMA (IEC = $1.51 \mathrm{mmol} \mathrm{g}^{-1}, 15 \mathrm{mS} \mathrm{cm}{ }^{-1}, \lambda=12.8$ ) [47] containing a flexible trimethylammonium side chain, which have higher $\lambda$ values, and cannot attain a hydroxide conductivity similar to that of PAES-8TMA-0.15. These comparisons indicate that the PAES-8TMA- $x$ architecture can effectively utilize water and improve hydroxide ion conduction.

Fig. 3d compares the relationship between hydroxide ion conductivity and swelling ratio of PAES-8TMA- $x$ AEMs with others reported. Hydroxide ion conductivity increases with the swelling ratio, but at a lower level $(<14 \%)$ compared with other types of AEMs (whether lower or comparable IEC). For example, a poly(aryl ether ketone) AEM with four flexible morpholine side chains (PAEK-MmOH-30, IEC $=1.57 \mathrm{mmol} \mathrm{g}^{-1}$ ) [25] had a hydroxide conductivity of $32 \mathrm{mS} \mathrm{cm}^{-1}$ and swelling ratio of $21.8 \%$, respectively. A poly(arylene ether sulfone) AEM grafted with imidazolium-functionalized flexible side chains (ImPES-0.45, IEC $=1.95 \mathrm{mmol} \mathrm{g}^{-1}$ ) had a hydroxide conductivity of $43.4 \mathrm{mS} \mathrm{cm}{ }^{-1}$ and swelling ratio of $33.3 \%$, respectively [30]. Multiple cations attached to the flexible side chains not only effectively promote hydro- xide ion conduction, but also maintain excellent dimensional stability in PAES-8TMA- $x$ AEMs.

\section{Membrane morphology}

Polarity differences between the hydrophobic polymer backbone and hydrophilic cationic groups induce microphase separation self-assembly of water-rich ion conducting channels. Atomic force microscopy (AFM) was used to study the microstructures of the AEMs. In Fig. 4a, the bright regions represent the hydrophobic domains formed by the polymer backbone and the dark regions represent the hydrophilic domains formed by the quaternary ammonium ions. Clear ion clusters and hydrophilic domains of PAES-8TMA- $x$ ( $x=0.15$ and 0.35$)$ AEMs are readily observed. The introduction of eight flexible side-chain cationic groups on one repeat unit of the backbone not only improves the mobility and selfassembly of cations, but also increases the local density of ionic groups, which promotes the formation of cationic clusters (Fig. 4b). The AFM shows the most distinct and interconnected dark hydrophilic channels, and the horizontal width of the ion clusters measured from these AFM images is about $12-25 \mathrm{~nm}$.

\section{Thermal stability and mechanical properties}

The thermal weight loss curves of PAES-8TMA- $x$ measured by TGA in $\mathrm{N}_{2}$ atmosphere are shown in Fig. 4c. All samples exhibit three degradation steps, between 50 to $120^{\circ} \mathrm{C}, 220$ to $370^{\circ} \mathrm{C}$ and 430 to $800^{\circ} \mathrm{C}$. The first stage is attributed to residual bound water and the volatilization of small molecules. The second stage corresponds to the degradation of the quaternary ammonium groups; with an increase in the quaternary ammonium groups content, there is a greater degradation mass loss. The third stage mass loss corresponds to the degradation of the polymer backbone. Temperatures corresponding to $10 \%$ membrane mass loss in $\mathrm{N}_{2}$ atmosphere are above $270^{\circ} \mathrm{C}$, indicating that the AEMs had good thermal stability similar to other AEMs [15,22,29].

Table 1 lists the mechanical properties of PAES-8TMA$x$ AEMs at ambient atmospheric and room temperature conditions. Membrane tensile strength (TS) is between 28.5 and $35.4 \mathrm{MPa}$, and tensile modulus (TM) is between 0.58 and $1.03 \mathrm{GPa}$. Due to plasticization with water, the tensile strengths and moduli decrease with increasing quaternary ammonium group content (or IEC value), while the elongation at break (EB), which is between $13.4 \%$ and $19.8 \%$, increases. The present AEMs have good mechanical properties compared with a number of reported aromatic AEMs. For example, ABA-TQA-90 (IEC 

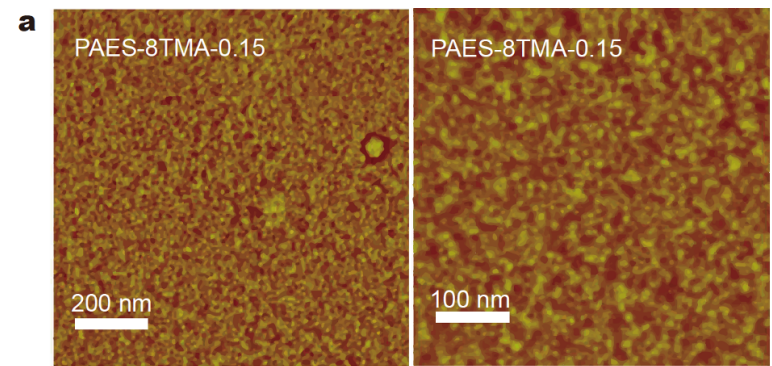

b

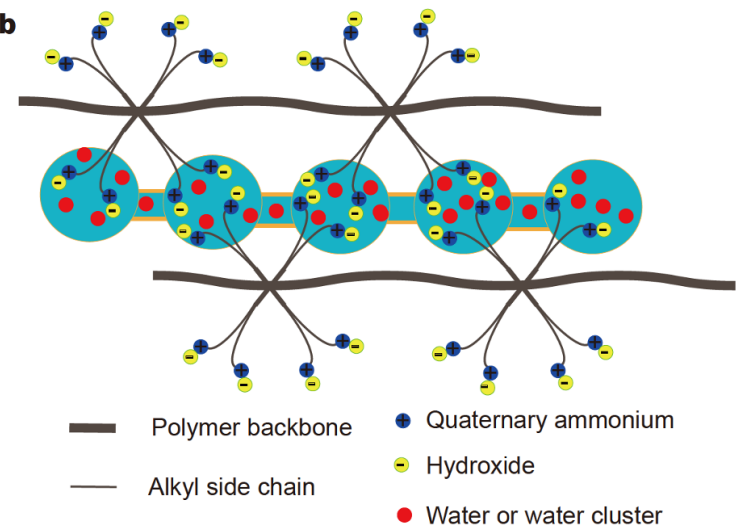

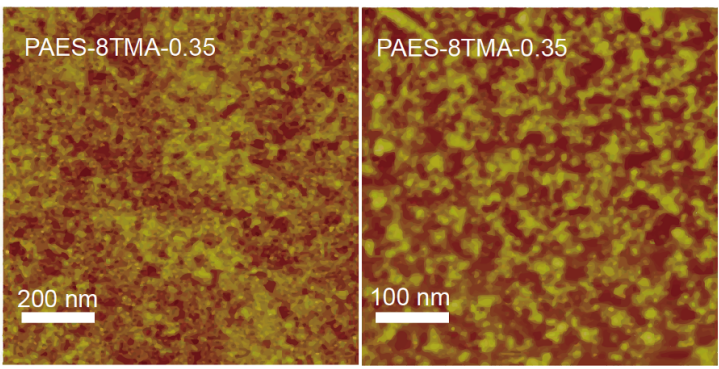

C

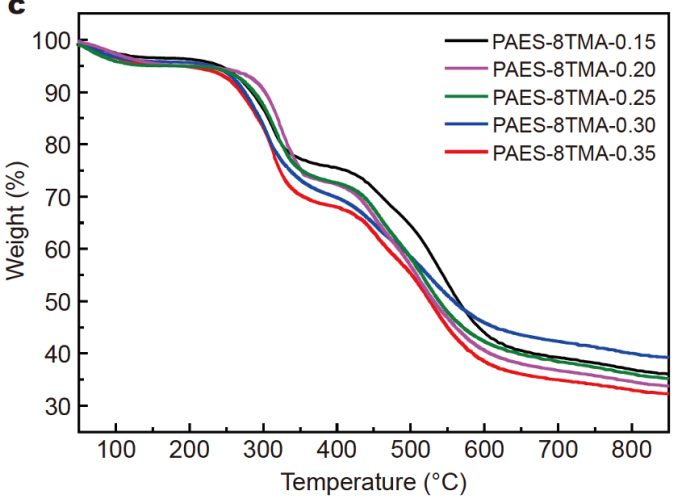

Figure 4 (a) AFM images of PAES-8TMA-0.15 and PAES-8TMA-0.35, (b) model of PAES-8TMA- $x$ and (c) TGA curves of the PAES-8TMA- $x$ membranes in $\mathrm{N}_{2}$.

$=1.94 \mathrm{mmol} \mathrm{g}^{-1}$ ) [13] had a tensile strength of $27.6 \mathrm{MPa}$ and an elongation at break of $10.6 \%$ in the hydrated state at room temperature.

\begin{abstract}
Alkaline stability
To simulate the alkaline conditions of AEMFC, PAES8TMA- $x$ membranes were immersed in $2 \mathrm{~mol} \mathrm{~L}^{-1} \mathrm{NaOH}$ at 60 and $90^{\circ} \mathrm{C}$. The alkaline stability of the membranes was evaluated by IEC and hydroxide conductivity changes after a certain period of time, and structural changes before and after immersion were analyzed by ${ }^{1} \mathrm{H}$ NMR. Fig. 5 a shows a comparison of the IEC values at specific time intervals. The IEC of the PAES-8TMA-0.35 membrane gradually decreases with the immersion time. At an immersion time of $480 \mathrm{~h}$ at 60 and $90^{\circ} \mathrm{C}, 85.0 \%$ and $82.2 \%$ of the initial IEC is retained, respectively. Fig. $5 \mathrm{~b}$ shows the hydroxide conductivity as a function of time, which is consistent with the experimental IEC trend. At an immersion time of $480 \mathrm{~h}$ at 60 and $90^{\circ} \mathrm{C}, 82.9 \%$ and $79.6 \%$ of the original hydroxide conductivity is retained, respectively. The present AEMs have good alkaline stability compared with many reported AEMs, even though they are susceptible to degradation under strong alkaline conditions.
\end{abstract}

In order to further determine the mechanism of de- gradation of PAES-8TMA- $x$ membranes, the structural changes of the copolymer before and after the alkali treatment were observed by ${ }^{1} \mathrm{H}$ NMR spectroscopy. Due to the complexity of the degradation process, the degree of degradation or the proportion of each degradation pathway cannot be quantified with certainty from the ${ }^{1} \mathrm{H}$ NMR spectra, because there are many possible alkali degradation mechanisms for quaternary ammonium cations (Fig. 5c). In addition, some degradation products such as trimethylamine (gas), $\mathrm{H}_{2} \mathrm{O}$, and $\mathrm{CH}_{3} \mathrm{OH}$ are difficult to capture. Fig. $5 \mathrm{~d}$ compares the ${ }^{1} \mathrm{H}$ NMR spectra of AEMs under different alkali stability test conditions. With increasing time, a new signal appears at $\sim 5.98 \mathrm{ppm}$, which is caused by degradation of the main chain [48]. The signal intensities at 3.83 and $3.07 \mathrm{ppm}$ are reduced, and two new signals at 2.00 and $3.93 \mathrm{ppm}$ are attributed to the degradation products of the quaternary ammonium groups. The decomposition of cationic groups is the main degradation pathways leading to a decrease in IEC and hydroxide ion conductivity.

Simple observation of the ${ }^{1} \mathrm{H}$ NMR spectra suggests that the AEMs undergo obvious degradation after 48-h immersion in $2 \mathrm{~mol} \mathrm{~L}^{-1} \mathrm{NaOH}$, which is consistent with the observed changes in IEC and hydroxide ion conductivity. However, compared with some reported 

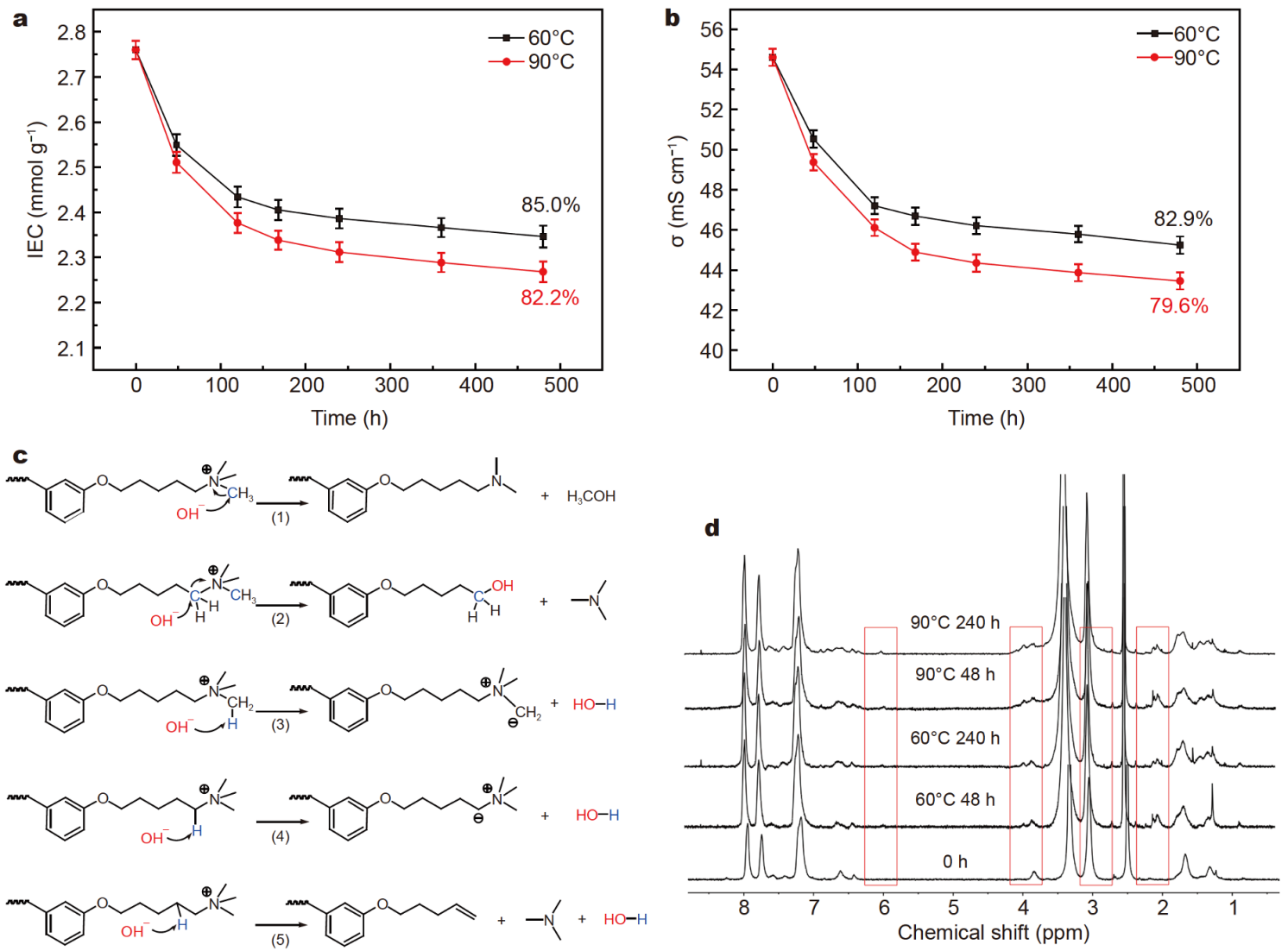

Figure 5 (a) IEC and (b) hydroxide conductivity at $30^{\circ} \mathrm{C}$ of the PAES-8TMA- 0.35 after immersion in a 2 mol L ${ }^{-1} \mathrm{NaOH}$ at 60 and $90^{\circ} \mathrm{C}$ for different time intervals. (c) Degradation mechanisms of alkyl quaternary ammonium in alkali environment. $(1,2)$ Substitution at $\alpha$-carbon, $(3,4) N$-Ylide formation and (5) Hofmann elimination; (d) ${ }^{1} \mathrm{H}$ NMR spectra of PAES-8TMA-0.35 after immersion in $2 \mathrm{~mol} \mathrm{~L}^{-1} \mathrm{NaOH}$ at 60 and $90^{\circ} \mathrm{C}$ for 0,48 and $480 \mathrm{~h}$.

AEMs, such as ImPES-0.45 (IEC $=1.84 \mathrm{mmol} \mathrm{g}^{-1}, 75 \%$ in $1 \mathrm{~mol} \mathrm{~L}^{-1} \mathrm{KOH}$ at $60^{\circ} \mathrm{C}$ for $196 \mathrm{~h}$ ) [30], CAPSF-10 (IEC $=1.73 \mathrm{mmol} \mathrm{g}^{-1}, 72 \%$ in $1 \mathrm{~mol} \mathrm{~L}^{-1} \mathrm{NaOH}$ at $60^{\circ} \mathrm{C}$ for $360 \mathrm{~h}$ ) [21], and PES-TMA (IEC $=1.51 \mathrm{mmol} \mathrm{g}^{-1}, 70 \%$ in $2 \mathrm{~mol} \mathrm{~L}^{-1} \mathrm{NaOH}$ at $60^{\circ} \mathrm{C}$ for $192 \mathrm{~h}$ ) [47], the alkaline stability of the PAES-8TMA- $x$ is obviously improved. The possible reason is that the incorporation of eight quaternary ammonium cationic groups on the repeating unit increases the local concentration of the ionic groups, forming a cationic cluster to confine $\mathrm{OH}^{-}$to the hydrophilic ion cluster, thus shielding the polymer backbone from $\mathrm{OH}^{-}$attack. In addition, higher hydration weakens the attack of $\mathrm{OH}^{-}$on quaternary ammonium ions, which improves the alkaline stability of the membrane $[49,50]$.

\section{CONCLUSIONS}

A novel bisfluorosulfone monomer containing octamethoxy groups was synthesized, from which a series of PAES with eight flexible side chain alkyl quaternary ammonium cations were prepared by sequential polycondensation, demethylation and grafting. Compared with some reported AEMs, the present AEMs with IEC of $1.76-2.76 \mathrm{mmol} \mathrm{g}^{-1}$ displayed superior overall properties, with desirable hydroxide ion conductivity, improved alkaline stability and low dimensional swelling ratio. An AEM with the best combination of properties, PAES8TMA-0.35, had a hydroxide ion conductivity of 43.6 and $125.0 \mathrm{mS} \mathrm{cm}^{-1}$ at 20 and $80^{\circ} \mathrm{C}$, respectively. After immersion in $2 \mathrm{~mol} \mathrm{~L}^{-1} \mathrm{NaOH}$ for $480 \mathrm{~h}$ at 60 and $90^{\circ} \mathrm{C}$ for the alkali stability test, $82.9 \%$ and $79.6 \%$ of hydroxide ion conductivity were retained, respectively. The incorporation of a high local density of flexible side-chain cations increases the aggregation and self-assembly by polarity differences between the hydrophobic polymer skeleton and the hydrophilic side chain, thus enhancing microphase separation and improving the overall AEM performance. The present work further expands the design and preparation of AEMs with architecture containing a high local density of flexible side chain cations. 
Received 29 April 2020; accepted 15 June 2020;

published online 19 August 2020

1 Chen Y, Liu Z, Lin M, et al. Selectivity enhancement of quaternized poly(arylene ether ketone) membranes by ion segregation for vanadium redox flow batteries. Sci China Chem, 2019, 62: 479-490

2 Xing Y, Liu L, Wang C, et al. Side-chain-type anion exchange membranes for vanadium flow battery: Properties and degradation mechanism. J Mater Chem A, 2018, 6: 22778-22789

3 Chen $\mathrm{Y}$, Lin $\mathrm{Q}$, Zheng $\mathrm{Y}$, et al. Densely quaternized anion exchange membranes synthesized from Ullmann coupling extension of ionic segments for vanadium redox flow batteries. Sci China Mater, 2019, 62: 211-224

4 Wang C, Shen B, Zhou Y, et al. Sulfonated aromatic polyamides containing nitrile groups as proton exchange fuel cell membranes. Int J Hydrogen Energy, 2015, 40: 6422-6429

5 Zhang J, He Y, Liang X, et al. Towards the gemini cation anion exchange membranes by nucleophilic substitution reaction. Sci China Mater, 2019, 62: 973-981

6 Wang C, Zhou Y, Shen B, et al. Proton-conducting poly(ether sulfone ketone)s containing a high density of pendant sulfonic groups by a convenient and mild post-sulfonation. Polym Chem, 2018, 9: 4984-4993

7 Xiong L, Hu YF, Zheng ZG, et al. Chloromethylation and quaternization of poly(aryl ether ketone sulfone)s with clustered electron-rich phenyl groups for anion exchange membranes. Chin J Polym Sci, 2020, 38: 278-287

8 Lin B, Xu F, Chu F, et al. Bis-imidazolium based poly(phenylene oxide) anion exchange membranes for fuel cells: The effect of cross-linking. J Mater Chem A, 2019, 7: 13275-13283

9 Ertem SP, Tsai TH, Donahue MM, et al. Photo-cross-linked anion exchange membranes with improved water management and conductivity. Macromolecules, 2016, 49: 153-161

10 Chen D, Hickner MA. Ion clustering in quaternary ammonium functionalized benzylmethyl containing poly(arylene ether ketone) s. Macromolecules, 2013, 46: 9270-9278

11 Zhang Y, Chen W, Yan X, et al. Ether spaced N-spirocyclic quaternary ammonium functionalized crosslinked polysulfone for high alkaline stable anion exchange membranes. J Membrane Sci, 2020, 598: 117650

12 Zhang X, Li S, Chen P, et al. Imidazolium functionalized block copolymer anion exchange membrane with enhanced hydroxide conductivity and alkaline stability via tailoring side chains. Int J Hydrogen Energy, 2018, 43: 3716-3730

13 Lin CX, Wu HY, Li L, et al. Anion conductive triblock copolymer membranes with flexible multication side chain. ACS Appl Mater Interfaces, 2018, 10: 18327-18337

14 Shen $\mathrm{B}, \mathrm{Pu} \mathrm{H}$. Fluorene-containing poly(arylene ether sulfone)s with imidazolium on flexible side chains for anion exchange membranes. Int J Hydrogen Energy, 2019, 44: 11057-11065

15 Miyanishi S, Fukushima T, Yamaguchi T. Synthesis and property of semicrystalline anion exchange membrane with well-defined ion channel structure. Macromolecules, 2015, 48: 2576-2584

16 Zhang S, Wang Y, Gao X, et al. Enhanced conductivity and stability via comb-shaped polymer anion exchange membrane incorporated with porous polymeric nanospheres. J Membrane Sci, 2020, 597: 117750

17 Ge Q, Liang X, Ding L, et al. Guiding the self-assembly of hyperbranched anion exchange membranes utilized in alkaline fuel cells. J Membrane Sci, 2019, 573: 595-601
18 Ge X, He Y, Guiver MD, et al. Alkaline anion-exchange membranes containing mobile ion shuttles. Adv Mater, 2016, 28: 34673472

19 Zhu T, Sha Y, Firouzjaie HA, et al. Rational synthesis of metallocations toward redox- and alkaline-stable metallo-polyelectrolytes. J Am Chem Soc, 2020, 142: 1083-1089

20 Zhou J, Zuo P, Liu Y, et al. Ion exchange membranes from poly (2,6-dimethyl-1,4-phenylene oxide) and related applications. Sci China Chem, 2018, 61: 1062-1087

21 Jiang Y, Wang C, Pan J, et al. Constructing an internally crosslinked structure for polysulfone to improve dimensional stability and alkaline stability of high performance anion exchange membranes. Int J Hydrogen Energy, 2019, 44: 8279-8289

22 Weiber EA, Jannasch P. Anion-conducting polysulfone membranes containing hexa-imidazolium functionalized biphenyl units. J Membrane Sci, 2016, 520: 425-433

23 Yang Q, Li L, Lin CX, et al. Hyperbranched poly(arylene ether ketone) anion exchange membranes for fuel cells. J Membrane Sci, 2018, 560: 77-86

24 Shukla G, Shahi VK. Poly(arylene ether ketone) copolymer grafted with amine groups containing a long alkyl chain by chloroacetylation for improved alkaline stability and conductivity of anion exchange membrane. ACS Appl Energy Mater, 2018, 1: 1175-1182

25 Yan X, Deng R, Pan Y, et al. Improvement of alkaline stability for hydroxide exchange membranes by the interactions between strongly polar nitrile groups and functional cations. J Membrane Sci, 2017, 533: 121-129

26 Sana B, Das A, Jana T. Polybenzimidazole as alkaline anion exchange membrane with twin hydroxide ion conducting sites. Polymer, 2019, 172: 213-220

27 Yang K, Chu X, Zhang X, et al. The effect of polymer backbones and cation functional groups on properties of anion exchange membranes for fuel cells. J Membrane Sci, 2020, 603: 118025

28 Qaisrani NA, Ma L, Liu J, et al. Anion exchange membrane with a novel quaternized ammonium containing long ether substituent. J Membrane Sci, 2019, 581: 293-302

29 Chen N, Long C, Li Y, et al. Ultrastable and high ion-conducting polyelectrolyte based on six-membered $\mathrm{N}$-spirocyclic ammonium for hydroxide exchange membrane fuel cell applications. ACS Appl Mater Interfaces, 2018, 10: 15720-15732

30 Guo D, Lai AN, Lin CX, et al. Imidazolium-functionalized poly (arylene ether sulfone) anion-exchange membranes densely grafted with flexible side chains for fuel cells. ACS Appl Mater Interfaces, 2016, 8: 25279-25288

31 Wang C, Zhou Y, Xu C, et al. Synthesis and properties of new sidechain-type poly(arylene ether sulfone)s containing tri-imidazole cations as anion-exchange membranes. Int J Hydrogen Energy, 2018, 43: 20739-20749

32 Wang C, Tao Z, Zhao X, et al. Poly(aryl ether nitrile)s containing flexible side-chain-type quaternary phosphonium cations as anion exchange membranes. Sci China Mater, 2020, 63: 533-543

33 Xue B, Wang F, Zheng J, et al. Highly stable polysulfone anion exchange membranes incorporated with bulky alkyl substituted guanidinium cations. Mol Syst Des Eng, 2019, 4: 1039-1047

34 Zhu T, Xu S, Rahman A, et al. Cationic metallo-polyelectrolytes for robust alkaline anion-exchange membranes. Angew Chem Int Ed, 2018, 57: 2388-2392

35 Akiyama R, Yokota N, Otsuji K, et al. Structurally well-defined anion conductive aromatic copolymers: Effect of the side-chain 
length. Macromolecules, 2018, 51: 3394-3404

36 Arges CG, Zhang L. Anion exchange membranes' evolution toward high hydroxide ion conductivity and alkaline resiliency. ACS Appl Energy Mater, 2018, 1: 2991-3012

37 Mayadevi TS, Sung S, Chae JE, et al. Quaternary ammoniumfunctionalized poly(ether sulfone ketone) anion exchange membranes: The effect of block ratios. Int J Hydrogen Energy, 2019, 44: 18403-18414

38 Vandiver MA, Caire BR, Pandey TP, et al. Effect of hydration on the mechanical properties and ion conduction in a polyethylene- $b$ poly(vinylbenzyl trimethylammonium) anion exchange membrane. J Membrane Sci, 2016, 497: 67-76

39 Li X, Nie G, Tao J, et al. Assessing the influence of side-chain and main-chain aromatic benzyltrimethyl ammonium on anion exchange membranes. ACS Appl Mater Interfaces, 2014, 6: 75857595

40 Dang HS, Jannasch P. Exploring different cationic alkyl side chain designs for enhanced alkaline stability and hydroxide ion conductivity of anion-exchange membranes. Macromolecules, 2015, 48: 5742-5751

41 Zheng J, Zhang Q, Qian H, et al. Self-assembly prepared anion exchange membranes with high alkaline stability and organic solvent resistance. J Membrane Sci, 2017, 522: 159-167

42 Shin DW, Guiver MD, Lee YM. Hydrocarbon-based polymer electrolyte membranes: Importance of morphology on ion transport and membrane stability. Chem Rev, 2017, 117: 4759-4805

43 Zhu L, Pan J, Wang Y, et al. Multication side chain anion exchange membranes. Macromolecules, 2016, 49: 815-824

44 Dang HS, Jannasch P. High-performing hydroxide exchange membranes with flexible tetra-piperidinium side chains linked by alkyl spacers. ACS Appl Energy Mater, 2018, 1: 2222-2231

45 Wang C, Shen B, Xu C, et al. Side-chain-type poly(arylene ether sulfone)s containing multiple quaternary ammonium groups as anion exchange membranes. J Membrane Sci, 2015, 492: 281-288 Wang C, Xu C, Shen B, et al. Stable poly(arylene ether sulfone)s anion exchange membranes containing imidazolium cations on pendant phenyl rings. Electrochim Acta, 2016, 190: 1057-1065

47 Liu FH, Lin CX, Hu EN, et al. Anion exchange membranes with well-developed conductive channels: Effect of the functional groups. J Membrane Sci, 2018, 564: 298-307

48 Mohanty AD, Tignor SE, Krause JA, et al. Systematic alkaline stability study of polymer backbones for anion exchange membrane applications. Macromolecules, 2016, 49: 3361-3372

49 Dekel DR, Amar M, Willdorf S, et al. Effect of water on the stability of quaternary ammonium groups for anion exchange membrane fuel cell applications. Chem Mater, 2017, 29: 4425-4431

50 Gottesfeld S, Dekel DR, Page M, et al. Anion exchange membrane fuel cells: Current status and remaining challenges. J Power Sources, 2018, 375: 170-184

Acknowledgements This work was supported by the Six Talent Peaks Project of Jiangsu Province (XCL-078), the Postgraduate Research \& Practice Innovation Program of Jiangsu Province (KYCX20-2528) and the Project Funded by the Priority Academic Program Development of Jiangsu Higher Education Institutions of China.

Author contributions Wang $\mathrm{C}$ and Guiver $\mathrm{M}$ designed the experiments; Tao Z and Zhou Y performed the experiments; Wang C, Tao Z and Guiver $M$ analyzed the data and wrote the paper. Zhao X, Li J, Ren
Q and all the other listed authors contributed to the general discussion.

Conflict of interest The authors declare that they have no conflict of interest.

Supplementary information Experimental details and supporting data are available in the online version of the paper.

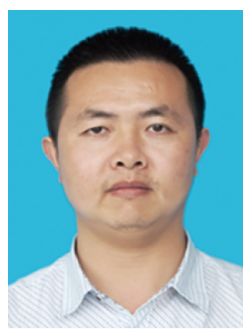

Chenyi Wang is an associate professor at the School of Materials Science and Engineering, Changzhou University. He obtained his $\mathrm{PhD}$ in polymer chemistry and physics from Donghua University in 2010 . He was a postdoctoral fellow from 2010 to 2012 at Hanyang University, South Korea. His research involves the development of high performance polymeric materials for fuel cells, flow batteries, and microelectronics devices.

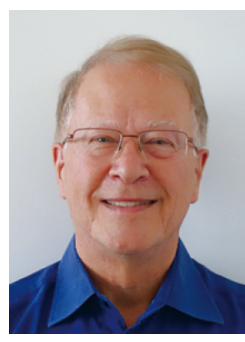

Michael D. Guiver obtained his $\mathrm{PhD}$ in chemistry from Carleton University in 1988. From 1987 to 2014, he worked at the National Research Council Canada. He was a visiting professor from 2009 at Hanyang University, South Korea. In 2014, he assumed a full-time position in Tianjin University, China. He has been an editor for the Journal of Membrane Science since 2009. His research interests are in polymeric membranes for ion-exchange and gas separation applications.

\section{具有改善电导率和碱稳定性的含八柔性侧链阳离 子结构的阴离子交换膜}

汪称意 ${ }^{1 *}$, 陶正旺 ${ }^{1}$, 周远鹏 ${ }^{1}$, 赵晓燕 ${ }^{1}$, 李坚 ${ }^{1}$, 任强 ${ }^{1}$, Michael D. Guiver ${ }^{2,3^{*}}$

摘要 增加阴离子交换膜(AEMs)亲水段中柔性侧链阳离子的局部 聚集度有助于改善膜材料的性能. 然而, 受结构设计策略和合成方 法的限制, 亲水链段局部含有四个以上柔性侧链阳离子结构的 $\mathrm{AEMs}$ 还鲜有报道. 为有效提高 $\mathrm{AEMs}$ 的离子传导率、碱稳定性和 尺寸稳定性，我们报道了一系列亲水链段局部含八个柔性侧链阳 离子的聚芳梄砜AEMs. 对所制膜材料(PAES-8TMA- $x$ ) 的结构、离 子交换容量(IEC)、吸水率、尺寸溶胀、碱稳定性和氢氧根电导率 进行了研究分析, 还系统比较了不同类型AEMs的结构与性能之间 的关系. IEC 值为 $1.76-2.76 \mathrm{mmol} \mathrm{g}^{-1}$ 的AEMs 表现出较全面的优良 性能, 其 $60^{\circ} \mathrm{C}$ 时的氢氧根电导率在 $62.7-92.8 \mathrm{mS} \mathrm{cm}^{-1}$, 尺寸溶胀在 8.3\%-15.8\%. 代表性的PAES-8TMA-0.35样品, 在 $90^{\circ} \mathrm{C}$ 的 $2 \mathrm{~mol} \mathrm{~L}^{-1}$ $\mathrm{NaOH}$ 中浸泡 $480 \mathrm{~h}$ 后, IEC和氢氧根电导率分别可保持初始值的 $82.9 \%$ 和 $79.6 \%$. 本研究工作延伸了局部含高密集柔性侧链阳离子 结构 AEMs 的设计和制备方法, 并为新型高性能AEMs材料的研制 提供了新的策略. 